\title{
The Effect of the Ball Size on the Product Characteristics of Shaker HEBM to Produce Nano Particle from Bamboo Charcoal
}

\author{
Supriyono Sastrowiyono \\ Department of Mechanical Engineering University of Muhammadiyah Surakarta, \\ Jl. A Yani Tromol Pos 1 Pabelan Kartosuro, Surakarta, Indonesia
}

\begin{abstract}
The objective of this research is to study the effect of ball size on characteristics of product of shaker high energy ball milling (HEBM) to produce nano particle from bamboo charcoal. A new shaker mechanism is developed. The characteristics of the particle are represented by particle size, surface morphology, and the substances presence in the product. Particle size analyzer (PSA) is conducted to have the particle sizes, whereas SEM and EDX are used to have surface morphology and substances presence in the products respectively. The mixtures of $11 \mathrm{gr}$ of bamboo charcoal powder of 200 meshes and about $299 \mathrm{gr}$ of steel ball are placed in vials. The vial is from stainless steel cylinder with $1 \frac{1}{4}$ inch diameter and $120 \mathrm{~mm}$ length. The stroke of the shaker is $54 \mathrm{~mm}$ at increasing speed of connecting rod pulley for every 1 million cycles. The total number of cycle is 3 million. Therefore, the connecting rod speed of the first 1 million cycles is $300 \mathrm{rpm}$, the second is 333 $\mathrm{rpm}$, and the third is $367 \mathrm{rpm}$. The steel ball sizes are $\frac{1}{8}, \frac{5}{32}, \frac{3}{16}$ and $\frac{1}{4}$ inch. PSA results indicate that there is no certain correlation between the steel ball size and particle size. The final shape of the particles is determined by fracture mechanism. The highest substance presence in the result is carbon and followed by silicon.
\end{abstract}

Keywords: bamboo; shaker; high energy ball milling; ultrafine powder

\section{INTRODUCTION}

High energy ball milling (HEBM) is usually referred to a process where a powder material located in the ball mill and is exposed to high-energy collision from the balls. HEBM sometimes called mechanical alloying is one of the most extensively technique used to produce ultrafine materials. It was developed in the mid 1960 by John Benjamin to produce nickel-based oxide dispersion strengthened (ODS) super alloys for gas turbine applications. HEBM process is widely used in ceramic and metal processing industries[1]. The process in HEBM consists of repeated fracture, mixing, and cold welding of a fine blend of metal, oxide, and alloy particles resulting in size reduction and sometimes in chemical reactions. In recent years the HEBM is employed to prepare nanostructured materials which are intensively studied. Different types of HEBM equipment are available for mechanical alloying and nanoparticle formation. They differ in their capacity, efficiency of milling, and additional arrangements for heat transfer and particle removal.

Examples of research in preparing nanostructured material using HEBM can be seen in [2] to [6]. H.F. Li and Ramanujan[2], studied the microstructure evolution and formation of nanocrystal line FeCo based alloys by mechanical alloying. S.R. Mishra,et al.,[3] conducted a research to study the magnetic properties of iron nitride-alumina nano-composite materials prepared by HEBM. R. Hamzaoui, et al.,[4] studied the structure and magnetic properties of nanocrystalline mechanically alloyed $\mathrm{Fe}-10 \mathrm{wt} \% \mathrm{Ni}$ 
and $\mathrm{Fe}-20$ wt\% $\mathrm{Ni}$ alloys of mixtures. W. Pilarczyk et al.,[5] did a research to study the structure and properties of $\mathrm{Fe}-\mathrm{Co}-\mathrm{Ni}$-B-Si-Nb alloy prepared by mechanical alloying method. El-Eskandarany et al.[6] studied the effect of milling speed in ball milling process. They said that the time required for the formation of an amorphous phase in the Co-Ti system decreased with an increase in the rotation speed.

Nanotubes, nanowires and nanorods are one-dimensional (1D) nano materials. They have many new properties, functionalities and a large range of promising applications. However, a major challenge for these future industrial applications is the large-quantity production. Ying Chen, et al., [7] reported that the ball milling and annealing process has the potential to achieve the mass production. In their work, several examples including $\mathrm{C}, \mathrm{BN}$ nanotubes and $\mathrm{SiC}, \mathrm{Zn}$ nanowires are presented to demonstrate such capability. In their study, two different types of HEBM mills have been used: a vertical rotating ball mill and a planetary ball mill. The experimental results show that HEBM has played an essential role in the formation of the above nanotubes and nanowires. Without the ball-milling process, many of them cannot be produced in the same annealing process.

In this research, shaker type of HEBM is used to produce nano particle from bamboo charcoal. A new shaker mechanism is developed. This research is part of the examination of the new mechanism to examine some variables which influence the nano particle results. This paper reports the effect of the ball size to the characteristics of the results.

On the other hand, there is a lot demand for nano particle of pure carbon in large quantities and low costs. Charcoal is one of the alternatives of carbon sources. In Indonesia the used of bamboo is very much which results in a lots of unused material. Bamboo has carbon content more than $90 \%$ of its weight [8]. It is a potential carbon source. The unused material of bamboo can be made to become charcoal. As far as, author's knowledge, there is very limited research on the bamboo as carbon source for nano-carbon particle. This research tries to have carbon nano-particle at large quantity and low cost production from bamboo.

\section{Methods}

Different types of HEBM have been developed. In this research, HEBM device of shaker type with a new shaker mechanism is developed (see Figure 2.1). The device consists of three main sub-assemblies i.e. control unit, motor, and shaker mechanism. The shaker mechanism is obtained from rotational motion transformed into translational motion by connecting rod. The length of the stroke is determined by the length of the connecting rod. The speed of the motor can be controlled and the ratio of the motor pulley to the connecting rod pulley is $1: 3$.

The vial is made from stainless steel cylinder with $1 \frac{1 / 4}{4}$ inch diameter and $120 \mathrm{~mm}$ length (see Figure 2.2). The contents of the vial are $11 \mathrm{gram}$ of bamboo charcoal powder of 200 meshes and about 299 gram of steel ball with diameter of $\frac{1}{8}, \frac{5}{32}, \frac{3}{16}$ and $\frac{1}{4}$ inch. Total four vials can be run at the same time to produce large quantities of materials.

The stroke of the shaker is $54 \mathrm{~mm}$. In this research, the HEBM decvice is run at increasing speed of connecting rod pulley for every 1 million cycles. The total number of cycle is 3 million. Therefore, the connecting rod speed at the first 1 million cycles is 300 $\mathrm{rpm}$, the second is $333 \mathrm{rpm}$, and the third is $367 \mathrm{rpm}$.

Characterization of the particle is conducted by Particle Size Analyzer (PSA), Scanning Electron Microscope (SEM) and Energy Dispersive X-Ray (EDX). The characteristics of the particle are represented by particle size, surface morphology, and the substances presence in the particle. 


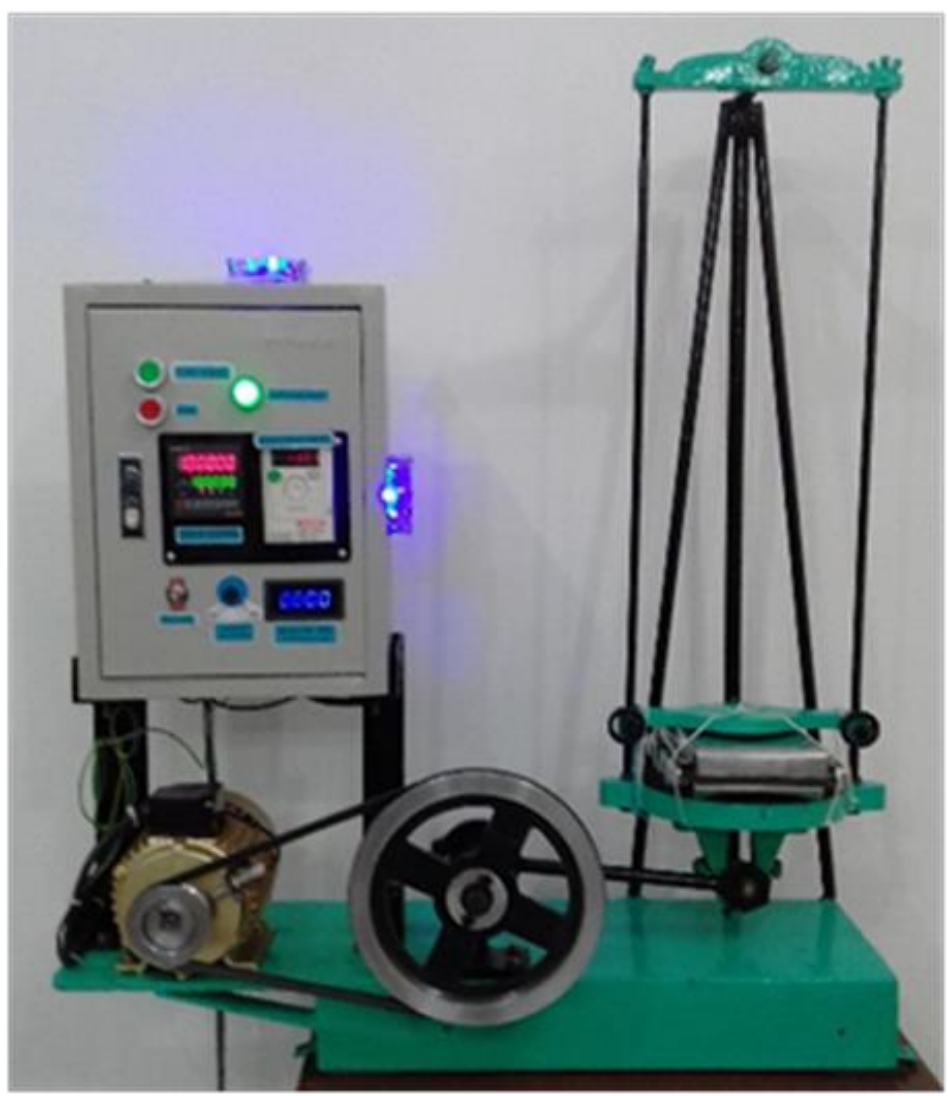

Figure 2.1 Shaker type of HEBM used in this research

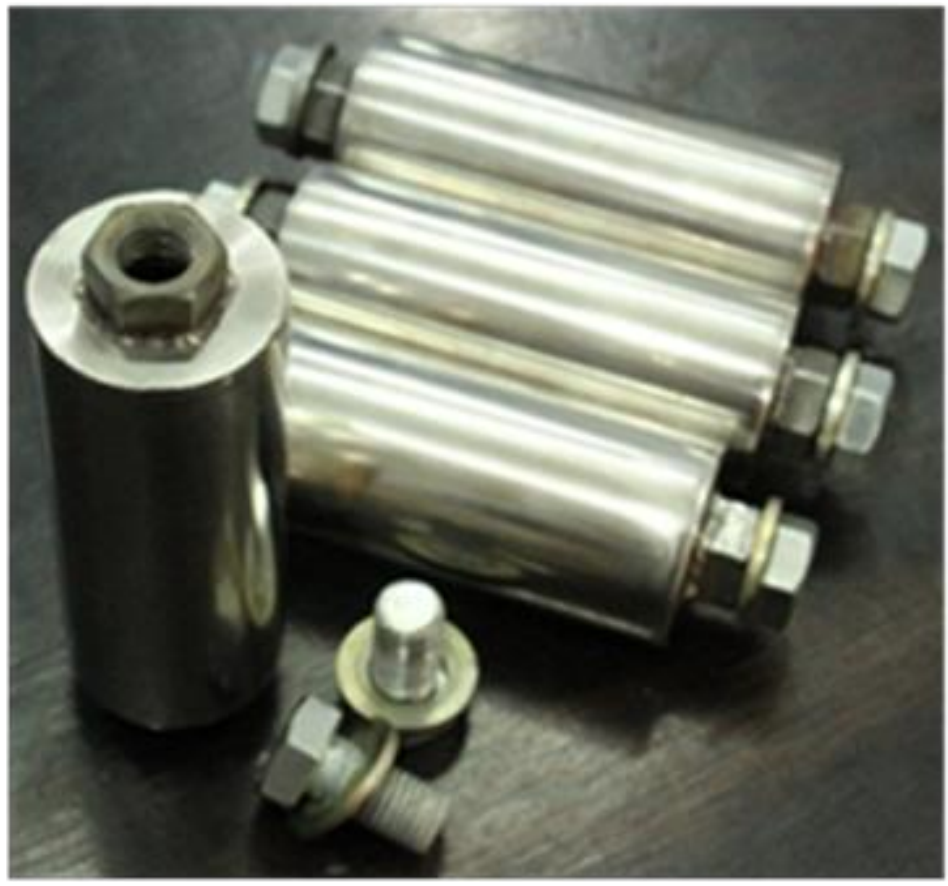

Figure 2.2 Vials used in this research 


\section{Result AND Discussion}

The results of particle size analyzer are shown in Table 2.1. It can be seen that the increase in diameter of the steel ball does not have any certain correlation to the decrease of the particle size. The smallest particle having average size of $314.0 \mathrm{~nm}$ is produced by the $3 / 16$ inch ball diameter. The sizes of $465.3 \mathrm{~nm}, 333.2 \mathrm{~nm}$ and $370.4 \mathrm{~nm}$ are produced by the $1 / 8,5 / 32$, and $1 / 4$ inch ball diameter respectively. The size reduction process is explained as follows : during the HEBM process, materials are repeatedly flattened, fractured and welded [7]. Every time two steel balls collide or one ball hits the vial wall, they trap some particles between their surfaces. The high-energy impacts severely deform the particles and create atomically fresh, new surfaces, as well as a high density of dislocations and other structural defects. Furthermore, the deformation and fracturing of particles cause continuous size reduction.

Table 2.1 Particle size analyzer results.

\begin{tabular}{cc}
\hline $\begin{array}{c}\text { Steel ball diameter } \\
\text { (inch) }\end{array}$ & $\begin{array}{c}\text { Average Particle Size } \\
\text { (nm) }\end{array}$ \\
\hline $1 / 8$ & 465.3 \\
$5 / 32$ & 333.2 \\
$3 / 16$ & 314.0 \\
$1 / 4$ & 370.4 \\
\hline
\end{tabular}

The increase in diameter means the increase in mass. At the same speed, it also means that the impact energy is increased. If the impact energy is higher, it should have more reduction in the particle size. In this research, it happens on the $1 / 8$ inch, the $5 / 32$ inch and $3 / 16$ inch steel ball diameter. However, it does not happen on $1 / 4$ inch steel ball diameter. This result indicates that the final particle size of HEBM depends on the material composition as it can be seen in the works by previous researchers. In this research, even though the dominant compound is carbon (more than $90 \%$ ), however the detail composition is different for each ball size (see Table 2.2)

According to the works by R. Ikono et al. [9] and J. Yan et al. [10] too long milling time cause agglomeration. Under SEM examination, the morphology of the agglomerated particles seems bigger than un-agglomerated particles. In this research, the agglomeration of the particles does not occur for all the ball sizes. It can be seen from the SEM results (see Figure 3.1 - Figure 3.4). The agglomerate particles will appear in sheets. The sheets do not appear in all SEM results.

Table 2.2 Particle composition

\begin{tabular}{ccccc}
\hline \multirow{2}{*}{ Compound } & \multicolumn{4}{c}{ Composition (\% weight) } \\
& $\begin{array}{c}\text { Steel ball } \\
\mathbf{1 / 8} \text { inchi }\end{array}$ & $\begin{array}{c}\text { Steel ball } \\
\mathbf{5 / 3 2} \text { inchi }\end{array}$ & $\begin{array}{c}\text { Steel ball } \\
\mathbf{3 / 1 6} \text { inchi }\end{array}$ & $\begin{array}{c}\text { Steel ball } \\
\mathbf{1 / 4} \text { inchi }\end{array}$ \\
\hline $\mathrm{C}$ & 95.78 & 92.26 & 95.31 & 92.49 \\
$\mathrm{~K}_{2} \mathrm{O}$ & 0.50 & 1.44 & 0.78 & 0.97 \\
$\mathrm{SiO}_{2}$ & 1.46 & 3.42 & 2.14 & 2.20 \\
$\mathrm{CaO}$ & 0.16 & 0 & 0 & 0.18 \\
$\mathrm{FeO}$ & 0.79 & 0.48 & 0.52 & 1.97 \\
$\mathrm{CuO}$ & 0.76 & 0.59 & 0.77 & 0.71 \\
$\mathrm{ZnO}$ & 0.54 & 0.59 & 0.48 & 0.39 \\
\hline
\end{tabular}


JEMMME, Vol.3, No. 1, May 2018

ISSN 2541-6332

e-ISSN 2548-4281

\begin{tabular}{ccccc}
\multicolumn{5}{c}{ Table 2.2 Particle composition (continued) } \\
\hline \multirow{5}{*}{ Compound } & $\begin{array}{c}\text { Composition (\% weight) } \\
\text { Steel ball } \\
\mathbf{1 / 8} \text { inchi }\end{array}$ & $\begin{array}{c}\text { Steel ball } \\
\mathbf{5 / 3 2} \text { inchi }\end{array}$ & $\begin{array}{c}\text { Steel ball } \\
\mathbf{3 / 1 6} \text { inchi }\end{array}$ & $\begin{array}{c}\text { Steel ball } \\
\mathbf{1 / 4} \text { inchi }\end{array}$ \\
\hline $\mathrm{P}_{2} \mathrm{O}_{5}$ & 0 & 0,87 & 0 & 0 \\
$\mathrm{Na}_{2} \mathrm{O}$ & 0 & 0 & 0 & 0 \\
$\mathrm{SO}_{3}$ & 0 & 0.32 & 0 & 0 \\
$\mathrm{ZrO}_{2}$ & 0 & 0.70 & 0 & 0.69 \\
$\mathrm{MgO}_{\mathrm{Al}_{2} \mathrm{O}_{3}}$ & 0 & 0 & 0 & 0.14 \\
\hline
\end{tabular}

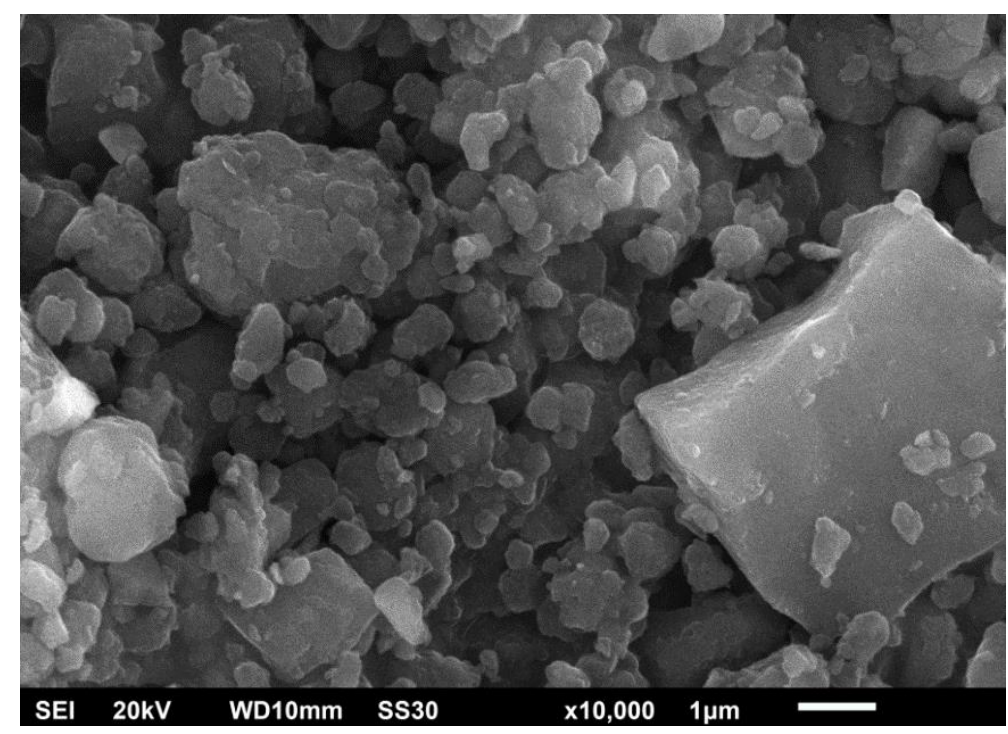

Figure 3.1 SEM morphology of 1/8 inch ball

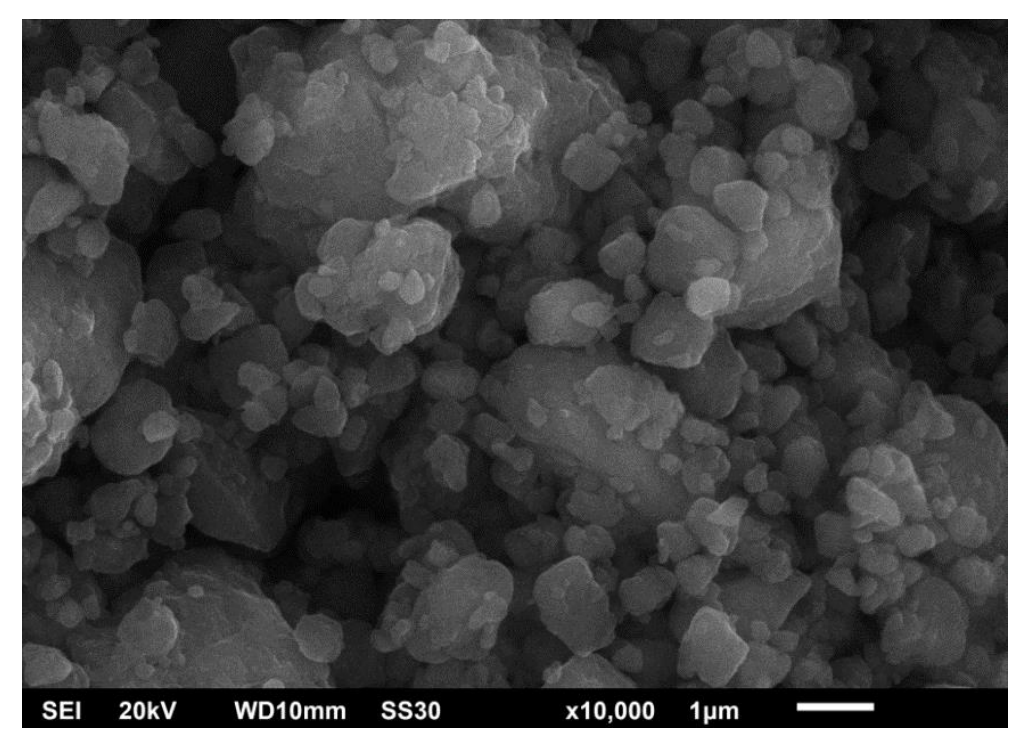

Figure 3.2 SEM morphology of 5/32 inch ball 


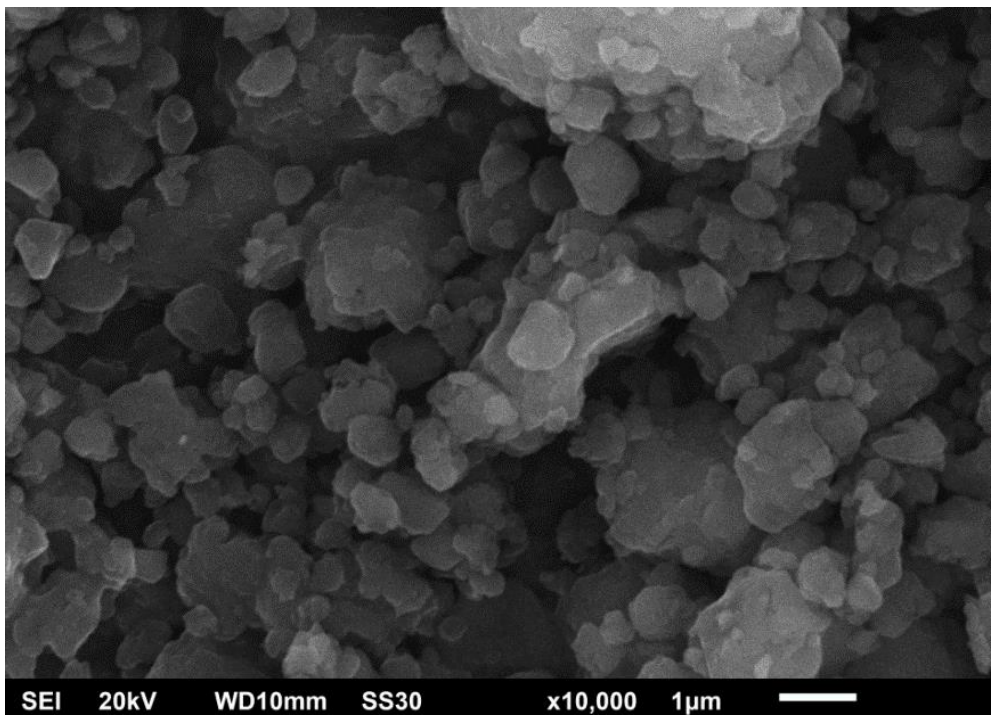

Figure 3.3 SEM morphology of 3/16 inch ball

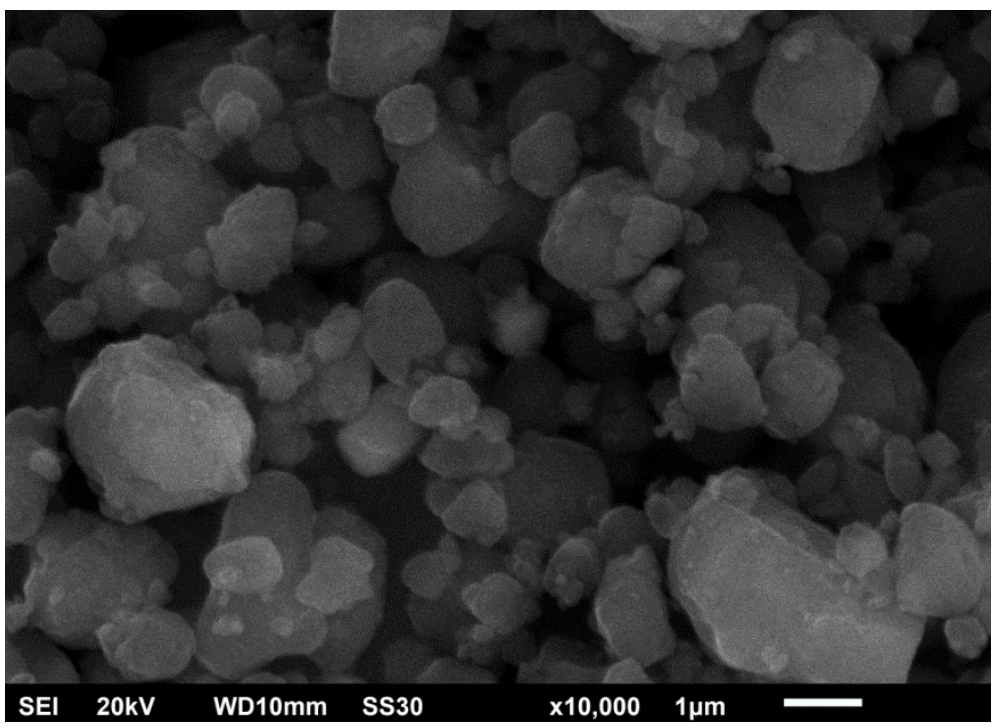

Figure 3.4 SEM morphology of 1/4 inch ball

If the impact energy is enough to prevent agglomeration, according a research conducted by Kim et al.,[11], there will be grinding limit. Grinding limit is condition at which the increase number of milling time has no effect on the particle size. Kim reported that after milling of Fe-Co powders for 30 hours, the milling process reached a steady state where the particles have become homogenized in size and shape. Other research, showing the grinding limit is done by J. Eckert and I. Borner [12]. After milling of Ni-Al powder for 100 hours, the particle size and shape become homogenous. Umemoto et al.,[13] conducted research on milling of Fe-C. After 500 hours milling time the grinding limit is reached and the particle size is $4.7 \mathrm{~nm}$ with homogenous shape.

The agglomeration does not happen for the all ball size after 3 million cycles. But grinding limit is not reached yet. SEM morphology of the particles as in Figure 3 to Figure 6 show this fact. It can be seen that the particle size is not homogenous yet. Even though 
the average size of the particle is less than $500 \mathrm{~nm}$ (as in PSA result), it can be seen that there are still particles with more than $1 \mu \mathrm{m}$.. The particles have fractional shape resulted from fracture mechanism.

Table 2 shows the substances presence in the particles as a result of EDX. It can be seen that the highest component is carbon. This result is in line with the result of $F$. G. Salihati and $\mathrm{H}$. Ardhyananta [8]. They reported that the carbon content of bamboo is more than $90 \%$ of its weight. The results show that the carbon content more than $90 \%$ of its weight. It can be said that bamboo is the right alternative carbon producer because it is a renewable natural resource. Bamboo is a type of biomass that has been widely cultivated. Currently, bamboo resources are abundant and the area of bamboo is about five million hectares. Bamboo, like wood, is composed of hemicellulose, cellulose and lignin. It has great potential as a future bio-energy resource.

\section{Conclusion}

The new shaker mechanism of HEBM device developed in this research can be used to prepare nano particle from bamboo charcoal. The size reduction depends on the impact energy. The final shape of the particle is determined by fracture mechanism. The most dominant element presence is carbon, it seems that bamboo charcoal is a potential source to produce nano carbon.

\section{REFERENCES}

[1] K. V Nagesha, M. Rajanish, and D. Shivappa, "A Review On Mechanical Alloying," Int. J. Eng. Res. Appl., vol. 3, no. 3, pp. 921-924, 2013.

[2] H. F. Li and R. V. Ramanujan, "Microstructural Evolution and Nanocrystalline Formation Kinetics in FeCo Based Alloys During Mechanical Alloying," J. Metastable Nanocrystalline Mater., vol. 23, pp. 187-190, 2005.

[3] S. R. Mishra et al., "Magnetic properties of iron nitride-alumina nanocomposite materials prepared by high-energy ball milling," Eur. Phys. J. D - At. Mol. Opt. Phys., vol. 24, no. 1-3, pp. 93-96, 2003.

[4] R. Hamzaoui, S. Guessasma, and O. ElKedim, "Analysis of structure and magnetic properties of nanocrystalline milled alloys," J. Alloys Compd., vol. 462, no. 1-2, pp. 29-37, 2008.

[5] A. P. W. Pilarczyk, R. Nowosielski, "Structure and properties of Fe-Co-Ni-B-Si-Nb alloy prepared by mechanical alloying method," J. Achiev. Mater. Manuf. Eng., vol. 30, no. 2, 2008.

[6] M. El-Eskandarany, K. Aoki, and K. Sumiyama, "Cyclic phase transformations of mechanically alloyed Co 75 Ti 25 powders," Acta, vol. 50, pp. 1113-1123, 2002.

[7] Y. C. Ã, C. P. Li, H. Chen, and Y. Chen, "One-dimensional nanomaterials synthesized using high-energy ball milling and annealing process," Sci. Technol. Adv. Mater., vol. 7, no. 2006, pp. 839-846, 2007.

[8] H. Sa'diyah, S. Nurhimawan, S. A. Fatoni, Irmansyah, and Irzaman, "Ektraksi silikon dioksida dari daun bambu," Pros. Semin. Nas. Fiz., vol. V, no. Oktober, pp. 13-16, 2016.

[9] R. Ikono et al., "SINTESIS NANOPARTIKEL ZnO DENGAN METODE MECHANOCHEMICAL MILLING," pp. 60-62, 2012.

[10] J. W. Yan, Y. Liu, A. F. Peng, and Q. G. Lu, "Fabrication of nano-crystalline W-NiFe pre-alloyed powders by mechanical alloying technique," Trans. Nonferrous Met. Soc. China (English Ed., vol. 19, no. SUPPL. 3, pp. s711-s717, 2009.

[11] Y. Do, J. Youl, J. Kim, and H. Jeon, "Formation of nanocrystalline Fe - Co powders produced by mechanical alloying," Mater. Sci. Eng., vol. 291, pp. 17-21, 2000. 
[12] J. Eckert and I. Bo, "Nanostructure formation and properties of ball-milled NiAI intermetallic compound," Mater. Sci. Eng., vol. 240, pp. 619-624, 1997.

[13] M. Umemoto, Z. G. Liu, K. Masuyama, X. J. Hao, and K. Tsuchiya, "Nanostructured Fe-C Alloys Produced by Ball Milling," Scr. Mater., vol. 44, pp. 1741-1745, 2001. 